\title{
Characteristics of Case Management in Primary Care Associated With Positive Outcomes for Frequent Users of Health Care: A Systematic Review
}

\author{
Catherine Hudon, MD, PbD, CFPC ${ }^{1}$ \\ Maud-Christine Chouinard, RN, \\ $P b D^{2}$ \\ Pierre Pluye, $M D, P b D^{3}$ \\ Reem El Sherif, MSc ${ }^{3}$ \\ Paula Louise Bush, $\mathrm{PbD}^{3}$ \\ Benoît Riboux, $\mathrm{PbD}^{4}$ \\ Marie-Eve Poitras, RN, $\mathrm{PbD}^{2}$ \\ Mireille Lambert, $M A^{5}$ \\ Hervé Tchala Vignon Zomaboun, \\ $\mathrm{PbD}{ }^{6}$
}

\section{France Légaré, $M D, P b D, C F P C^{7}$}

'Département de Médecine de Famille et de Médecine d'Urgence, Université de Sherbrooke, Québec, Canada

${ }^{2}$ Département des Sciences de la Santé, Université du Québec à Chicoutimi, Québec, Canada

${ }^{3}$ Département de Médecine de Famille, Université McGill, Québec, Canada

${ }^{4}$ Institut de Sciences Politiques LouvainEurope (ISPOLE), Université Catholique de Louvain, Louvain-la-Neuve, Belgium

${ }^{5}$ Centre Intégré Universitaire de Santé et Services Sociaux du Saguenay-Lac-SaintJean, Québec, Canada

${ }^{6}$ Centre de Recherche du CHU de Québec - Université Laval, Québec, Canada

${ }^{7}$ Département de Médecine Familiale et de Médecine d'Urgence, Université Laval, Québec, Canada

Conflicts of interest: authors report none.

\section{CORRESPONDING AUTHOR}

Catherine Hudon, MD, PhD

Département de Médecine de Famille et de Médecine d'Urgence

Université de Sherbrooke, Pavillon

Z7-local 3007

3001, 12e Avenue Nord

Sherbrooke, Québec, J1H 5N4

Catherine.Hudon@usherbrooke.ca

\begin{abstract}
PURPOSE Case management (CM) interventions are effective for frequent users of health care services, but little is known about which intervention characteristics lead to positive outcomes. We sought to identify characteristics of CM that yield positive outcomes among frequent users with chronic disease in primary care.
\end{abstract}

METHODS For this systematic review of both quantitative and qualitative studies, we searched MEDLINE, CINAHL, Embase, and PsycINFO (1996 to September 2017) and included articles meeting the following criteria: (1) population: adult frequent users with chronic disease, (2) intervention: CM in a primary care setting with a postintervention evaluation, and (3) primary outcomes: integration of services, health care system use, cost, and patient outcome measures. Independent reviewers screened abstracts, read full texts, appraised methodologic quality (Mixed Methods Appraisal Tool), and extracted data from the included studies. Sufficient and necessary CM intervention characteristics were identified using configurational comparative methods.

RESULTS Of the 10,687 records retrieved, 20 studies were included; 17 quantitative, 2 qualitative, and 1 mixed methods study. Analyses revealed that it is necessary to identify patients most likely to benefit from a CM intervention for CM to produce positive outcomes. High-intensity intervention or the presence of a multidisciplinary/interorganizational care plan was also associated with positive outcomes.

CONCLUSIONS Policy makers and clinicians should focus on their case-finding processes because this is the essential characteristic of CM effectiveness. In addition, value should be placed on high-intensity CM interventions and developing care plans with multiple types of care providers to help improve patient outcomes.

Ann Fam Med 2019;17:448-458. https://doi.org/10.1370/afm.2419.

\section{INTRODUCTION}

I n developed countries, the bulk of health care system expenses is attributable to a small proportion of the population. Specifically, frequent users of health care services account for approximately $10 \%$ of the population but upward of $70 \%$ of health care expenditures. ${ }^{1-3}$ Many frequent users have chronic physical diseases that are further complicated by mental health comorbidities and/or social vulnerabilities, which increase their overall health care needs. ${ }^{4,5}$ These individuals are more likely to experience fragmentation of care, ${ }^{6,7}$ suffer from disability, ${ }^{8}$ and have a general decrease in quality of life ${ }^{9}$ and an increased risk of death. ${ }^{10,11}$

A variety of interventions have been developed to improve the health and social care of frequent users, the most common of which are case management $(\mathrm{CM})$, individualized care plans, patient education and counseling, problem solving, and information sharing. ${ }^{12-17}$ Case management is a promising and effective intervention to improve the health and social care of frequent users ${ }^{12-17} ;$ it is a collaborative approach to ensure, coordinate, and integrate care and services for patients, in which a case 
manager evaluates, plans, implements, coordinates, and prioritizes services on the basis of patients' needs in close collaboration with other health care providers. ${ }^{18}$ Many literature reviews have reported the effectiveness of CM interventions, citing such benefits as reductions in emergency department (ED) visits and hospital admissions, overall reductions in expenditures, and improved patient outcomes such as quality of life and patient satisfaction. ${ }^{12-15,19,20}$ However, CM is a complex intervention, with various characteristics interacting in a nonlinear manner. ${ }^{21,22}$ To design and implement effective CM interventions, we need to understand the characteristics of CM that are associated with positive outcomes. The objective of the present study was to conduct a systematic review to identify characteristics of CM that yield positive outcomes among adult frequent users with chronic disease in primary care.

\section{METHODS}

We conducted a systematic review including quantitative, qualitative, and mixed methods studies, with a data-based convergent synthesis design. ${ }^{23}$ This type of design, combining the strengths of quantitative and qualitative research, helps to develop a rich and deep understanding of complex health interventions. ${ }^{23,24}$ Our complete methods are detailed in a peer-reviewed systematic review protocol that is registered on PROSPERO (CRD42016048006). ${ }^{25}$

\section{Eligibility Criteria}

The eligibility criteria were as follows: (1) population: adult frequent users (aged $\geq 18$ years) with physical chronic disease and receiving care in primary, secondary, tertiary, or community care settings, (2) intervention: CM in a primary care setting (including ED) with a postintervention evaluation, and (3) primary outcomes: integration of services, health care system use, financial cost, and patient outcomes (eg, self-management, patient experience of care, health-related quality of life, etc). To increase homogeneity of the sample of included studies and comparability of CM characteristics between studies, pediatric, frail elderly, and homeless populations were excluded because these populations might have distinct sets of needs. In addition, specific diseaseoriented CM interventions were excluded because primary care aims to improve whole-person health.

\section{Information Sources and Search Strategy}

A bibliographic database search was conducted of the online databases MEDLINE, CINAHL, Embase, and PsycINFO for empirical studies (experimental, quasiexperimental, qualitative, and mixed methods studies) published in English or French and limited to the past
20 years (ie, 1996 to September 2017). An information specialist for Cochrane Canada Francophone developed and ran specific search strategies for each database, combining the search concepts "frequent use" and "evaluation studies." The MEDLINE search strategy is presented in Supplemental Appendix 1 (http:// www.AnnFamMed.org/content/17/5/448/suppl/DC1/). Relevant studies were identified via a hand search of the reference lists of studies selected via the electronic search to be included in the review. To capture more information on CM interventions, companion documents (eg, protocols, reports, website pages, news articles) for each included study were retrieved by searching Google, ResearchGate, Scopus, and PubMed, as well as e-mailing the corresponding authors.

\section{Study Selection and Data Extraction}

Four reviewers participated in the study selection using Covidence systematic review software. Two independent reviewers (L.L., M-J.C; see acknowledgment in end copy for reviewers listed in this section) screened titles and abstracts using the eligibility criteria, and 2 other independent reviewers (M.S., V.G.) assessed full texts of the selected studies for eligibility. At both stages, discrepancies were resolved by a third reviewer (M.L.). Eligible studies were retained for data extraction and methodologic quality assessment. Two reviewers extracted the following data using a standardized data extraction form: study characteristics (eg, first author, year of publication, country, setting, design); definition of frequent users; population characteristics such as age and sex; sample size; type, objective, frequency, and content of intervention; length of intervention sessions; duration of patient follow-up; case-finding process; health care providers involved; intervention offered to control group; data analysis; outcome characteristics and assessment instruments; and intervention effectiveness according to reported outcomes (quantitative or qualitative). Data extraction was double-checked by a second reviewer.

\section{Quality Appraisal and Data Synthesis}

Two independent reviewers used the Mixed Methods Appraisal Tool (MMAT) ${ }^{26-29}$ to assess eligible studies and determine an overall methodologic quality score for each. When necessary, disagreements between reviewers were resolved by a third reviewer. The MMAT was specifically designed to concomitantly appraise studies with diverse designs and has been validated and reliability tested. ${ }^{26-29}$ We used the 2011 version of the MMAT, which includes 2 initial screening questions and 19 items. Studies that did not meet the 2 initial screening questions were deemed not empirical and were excluded. We performed a sensitivity analysis to assess the effect of methodologic quality on the results 
by replicating the analysis without the low-quality studies (MMAT score $\leq 25 \%) .{ }^{30}$ The MMAT has recently been updated and revalidated using a conceptual framework on the quality of qualitative, quantitative, and mixed methods studies included in mixed studies reviews $^{31}$; qualitative research ${ }^{32}$ with MMAT users worldwide; and a Delphi study with international experts. ${ }^{33}$ This led to the 2018 version of the MMAT. ${ }^{34}$ We used the original version for the present study.

Sufficient and necessary characteristics of CM interventions were identified using configurational comparative methods $(\mathrm{CCM})^{35}$; this is used to study a small to intermediate number of cases (eg, 5-50), among which an outcome of interest has been identified, ${ }^{36}$ allowing for the integration of quantitative and qualitative results. ${ }^{23}$ The use of CCM helps to identify configurations, that is, a combination of conditions that produces the presence or absence of the outcome of interest across cases. This allows for reduction of the complexity of data sets in small $\mathrm{N}$ situations by using Boolean algebra ${ }^{37}$ to explore different combinations of conditions and to identify necessary and sufficient conditions associated with the outcome of interest. A necessary condition is one that is always present when the outcome occurs, that is, the outcome cannot occur without this condition. A condition (or combination of conditions) is considered sufficient to produce an outcome if the outcome always occurs when the condition (or combination of conditions) is present. ${ }^{38}$ In the present study, the characteristics of CM interventions were the conditions we explored. Supplemental Appendix 2 (http://www.AnnFam Med.org/content/17/5/448/suppl/

Table 1. Description of Included Studies

\begin{tabular}{llll}
\hline $\begin{array}{l}\text { First Author, } \\
\text { Year, (Country) }\end{array}$ & Design & Setting & $\begin{array}{l}\text { Population (CM Intervention } \\
\text { Inclusion Criteria) }\end{array}$ \\
\hline $\begin{array}{c}\text { Adam et al }{ }^{40} \\
2010 \text { (USA) }\end{array}$ & $\begin{array}{c}\text { Nonrandomized } \\
\text { trial }\end{array}$ & $\begin{array}{c}\text { Primary care } \\
\text { clinic }\end{array}$ & $\begin{array}{c}\geq 8 \text { clinic visits/year with multiple } \\
\text { comorbidities (physical, psychiatric } \\
\text { and psychosocial issues) }\end{array}$
\end{tabular}

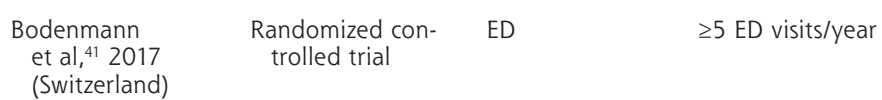

\begin{tabular}{|c|c|c|c|}
\hline $\begin{array}{l}\text { Brown et al, }{ }^{42} \\
2005 \text { (USA) }\end{array}$ & Before-after study & $\begin{array}{l}\text { Primary care } \\
\text { clinic }\end{array}$ & $\begin{array}{l}\geq 1 \text { hospital admission/year, } \geq 1 \\
\text { chronic condition, and life expec- } \\
\text { tancy judged to be greater than } \\
3 \text { years }\end{array}$ \\
\hline Crane et $\mathrm{al}^{43}$ & Nonrandomized & ED & 6 ED visits/year; low far \\
\hline
\end{tabular}

2012 (USA)

Edgren et $\mathrm{al}_{1}{ }^{44} \quad$ Randomized con- $\quad \mathrm{ED}$ 2016 (Sweden) trolled trial Grimmer-Somers
et al, ${ }^{45} 2010$ (Australia)

$\begin{array}{ccc} & & \\ \begin{array}{c}\text { Grinberg et al, } \\ 2016 \text { (USA) }\end{array} & \text { Qualitative study } & \begin{array}{c}\text { Transitional pri- } \\ \text { mary care - } \\ \text { postdischarge }\end{array} \\ \begin{array}{c}\text { Grover et al, }{ }^{47} \\ 2010 \text { (USA) }\end{array} & \text { Before-after study } & \text { ED } \\ & & \\ \text { Hudon et al, }{ }^{48} & \text { Qualitative study } & \begin{array}{c}\text { Primary care } \\ \text { clinics }\end{array}\end{array}$

$\begin{array}{ccc}\text { Mixed methods } & \text { Primary care } \\ \text { study } & \text { Venters }\end{array}$
centers

\section{$\geq 3$ ED visits/6 months, deemed at risk of high health care use and considered to be receptive to intervention}

$\geq 2$ hospital admissions/ 6 months with
at least 3 of the following criteria:
$\geq 2$ chronic conditions; $\geq 5$ outpa-
tient medications; lack of access to
health care services; lack of social
support; mental health comorbidity;
substance abuse or use; homeless
$\geq 5$ ED visits/month or concern about
ED use raised by staff or identified
by California prescription-monitor-
ing program

$\geq 3$ ED visits and/or hospital admissions/year, $\geq 1$ chronic condition, and identified by family physician as a frequent user likely to benefit from intervention 
I: $12 \quad$ Interdisciplinary care team developed care plan based on patient's C: 8 evaluation. Care plan could include referral to mental health services, review of medication, and care coordination. The PCP presented the care plan to the patient and amended it if needed.

I: 125

25 patients 8 family members
Interdisciplinary mobile team developed care plan based on patient's evaluation. Care plan could include assistance for financial entitlements, education, housing, health insurance, and domestic violence support, as well as referral to mental health services, substance abuse treatment, or a PCP. Team also provided care coordination, counseling on substance abuse (if needed) and use of medical services. They also facilitated communication between health care team members.

Interdisciplinary care team developed care plan based on patient's evaluation. Care plan could include referral for diagnostic testing or specialists' services and a review of medication. The team also provided care coordination, psychological support, self-management support, and disease management.

Interdisciplinary care team developed care plan based on patient's evaluation. Care plan could include referral for diagnostic testing or specialists' services and review of medication. The team also provided group and individual medical appointments, telephone access to care manager, and group sessions on life-skills support.

Nurse case manager developed, with patient, a care plan based on patient's evaluation. Care plan could include self-management support, patient education, and referrals to other health and social services. Via regular contact by telephone, case manager provided self-management support to patient. They also facilitated communication and supported interactions with health care providers and social services.

Interdisciplinary care team developed, with patient, care plan based on patient's evaluation. Care plan could include referrals to other health and social services, self-management support, patient education, goal setting, and involvement in peer-led community group. The team also provided support for language, literacy, social support, and transport barriers.

Interdisciplinary care team developed care plan based on patient's evaluation. Care plan could include access to primary care, review of medication, medical appointment accompaniment, assistance for transport, and financial entitlements. The team also provided care coordination and health navigation after hospital discharge.

Interdisciplinary care team developed care plan based on patient's evaluation. Care plan could include referrals to outpatient and social services as well as restriction of narcotics prescriptions. Patients received letters to inform them of the care plan but had no contact with the team. The care plan was entered in the patient's medical records in the ED for easy access to information by the ED staff.

Nurse case manager developed, with patient and other health care providers, a care plan based on patient's evaluation. Care plan could include referrals to health and social services and interdisciplinary team meetings (including the patient). The case manager also provided self-management support and care coordination. $\downarrow$ Clinic visits Quality Score, \%

$\uparrow$ Well-being

$\uparrow$ Patient satisfaction

$\uparrow$ Quality of care

$\uparrow$ No show or cancelled appointments

No change in hospital admission and ED use

No significant changes in ED visits

100

$\downarrow$ ED visits

$\downarrow$ Hospital admissions

$\downarrow$ Length of stay

No change in health care costs

$\downarrow$ ED visits

$\downarrow E D$ and inpatient costs

$\uparrow$ Employment status

$\downarrow$ Outpatient care

$\downarrow$ Inpatient care

$\downarrow$ ED visits

$\downarrow$ Health care costs

$\downarrow$ ED use

$\downarrow$ Hospital admissions

$\downarrow$ Length of stay

$\downarrow$ Inpatient cost

$\downarrow$ Outpatient attendance

$\uparrow$ Patient reflection on their health and other needs

$\uparrow$ Patient goal-setting

$\uparrow$ Patient motivation

$\uparrow$ Self-management

$\uparrow$ Healing relationships

$\downarrow$ ED use

$\downarrow$ Radiation exposure from diagnostic imaging

$\uparrow$ Efficacy of referral

No change in hospital admissions or most common chief complaint

$\uparrow$ Access to care

$\uparrow$ Communication

$\uparrow$ Care coordination

$\uparrow$ Patient involvement in decision-making

$\uparrow$ Care transition 
DC1/) provides definitions of CCM terms.

The CCM followed the 6 steps described by Rihoux and $\operatorname{Ragin}^{35}$ (a complete description of each step is detailed in Supplemental Appendix 3, http:// www.AnnFamMed.org/content/17/5/448/suppl/DC1/): (1) building a raw data table, (2) constructing a truth table, (3) resolving contradictory configurations,

(4) conducting Boolean minimization using fuzzy set/qualitative comparative analysis (fs/QCA) software, (5) bringing in the logical remainders cases (TOSMANA software was used to create a visual representation of our results), and (6) interpreting the results. Following best practices in CCM, the selection of conditions used in the analysis, and the way each condition was defined, was informed by case-based knowledge (data extraction) and CM theory. ${ }^{38}$ The number of conditions was limited so that the ratio between the number of possible logical combinations of conditions and the number of cases was kept sufficiently low. ${ }^{37,39}$ For example, for the thematic synthesis step of the present review, we identified main characteristics of CM interventions in the included studies (Table 1). Of those, we identified 4 initial conditions that were most commonly reported in the included studies (informed by the team's experience with $\mathrm{CM}$ and prior research on $\mathrm{CM}$ for frequent users). The definitions of these conditions were developed iteratively by drawing from prior research, going back to the cases to explore how they were defined, and drawing on the substantive and field knowledge of the team members. One condition (effective communication between health care providers) was removed because it was not reported or we were not able to
Table 1. Description of Included Studies (continued)

\begin{tabular}{|c|c|c|c|}
\hline $\begin{array}{l}\text { First Author, } \\
\text { Year, (Country) }\end{array}$ & Design & Setting & $\begin{array}{l}\text { Population (CM Intervention } \\
\text { Inclusion Criteria) }\end{array}$ \\
\hline $\begin{array}{l}\text { McCarty et al, }{ }^{49} \\
2015 \text { (USA) }\end{array}$ & Before-after study & ED & $\begin{array}{l}\geq 25 \text { ED visits/year or identified by } \\
\text { ED staff as frequent user likely to } \\
\text { benefit from intervention }\end{array}$ \\
\hline $\begin{array}{l}\text { Peddie et al, }{ }^{50} \\
2011 \text { (New } \\
\text { Zealand) }\end{array}$ & $\begin{array}{l}\text { Nonrandomized } \\
\text { trial }\end{array}$ & ED & $\geq 10$ ED visits/year \\
\hline $\begin{array}{l}\text { Pope et al, },^{51} 2000 \\
\text { (Canada) }\end{array}$ & Before-after study & ED & $\begin{array}{l}\text { Frequent users who had the poten- } \\
\text { tial for high ED use, with at least } \\
2 \text { of the following criteria: chronic } \\
\text { condition, complex medical condi- } \\
\text { tion, substance abuse user, violent } \\
\text { behavior or abusive behavior }\end{array}$ \\
\hline $\begin{array}{l}\text { Reinius et al, },^{52} \\
2013 \text { (Sweden) }\end{array}$ & $\begin{array}{l}\text { Randomized con- } \\
\text { trolled trial }\end{array}$ & ED & $\begin{array}{l}\geq 3 \text { ED visits/6 months with the } \\
\text { ability to participate in the study } \\
\text { based on medical history, number } \\
\text { of medications prescribed, and } \\
\text { social factors }\end{array}$ \\
\hline
\end{tabular}

Roberts et al, ${ }^{53} \quad$ Before-after study Transitional pri-

2015 (USA)

mary care -

postdischarge

$\geq 2$ hospital admissions/6 months or $\geq 3$ hospital admissions/year with $\geq 1$ chronic condition

Shah et al ${ }^{54} 2011 \quad$ Nonrandomized Primary care (USA) trial center

$\geq 4$ ED visits or hospital admissions or $\geq 3$ hospital admissions or $\geq 2$ hospital admissions and $1 \mathrm{ED}$ visit/ year, with low family income, uninsured, and not eligible for public health insurance program

Skinner et $\mathrm{al}_{1}, 5$

2009 (UK)

Before-after study

ED

$\geq 10$ ED visits/6 months or identified by senior health care providers as putting a high demand on unscheduled care services (or at future risk) and who could benefit from intervention

Sledge et $\mathrm{al}_{1}^{56}$ 2006 (USA)

Randomized con-

Primary care

$\geq 2$ hospital admissions/year trolled trial center

Randomized con-

ED

$\geq 10$ ED visits/year

1997 (USA)

trolled trial

Stokes-Buzzelli et al, ${ }^{58} 2010$ (USA)

Before-after study

ED

Top 100 frequent ED users, or identified as frequent users deemed appropriate for intervention

Weerahandi et al, ${ }^{59} 2015$ (USA) $\geq 1$ hospital admission/1 month or 2 hospital admissions/ 6 months
Transitional primary care postdischarge 
$\mathbf{N}$

23

I: 87

C: 77

24

I: $211 \quad$ Same intervention as Edgren et al $(2016)^{44}$ actions with community services.
Interdisciplinary care team developed, with patient, a care plan based care and social services, goal setting, crisis intervention, restriction of narcotic prescriptions, assistance for transport, financial entitlements, and housing. The team also provided care coordination and supported interactions with community services.

Interdisciplinary care team developed care plan based on patient's evaluation. The care plan could include referrals to a PCP and interdisciplinary team meeting (including the patient).

Interdisciplinary care team developed care plan based on patient's evaluation. Care plan could include referrals to health care and social services, restriction of narcotic prescriptions, restriction of ED use, limited interaction with ED staff, and escort by a security guard in the ED. The team also provided counseling and supported inter-

C: 57
Main Characteristics of the Intervention on patient's evaluation. Care plan could include referrals to health

Outcome

Methodological

Quality Score, \%

$\downarrow$ ED visits

50

No change in ED visits

$\downarrow$ ED visits

$\downarrow$ Outpatient care

50

$\downarrow$ ED visits

$\downarrow$ Length of stay

$\downarrow$ Health care costs

$\uparrow$ Health status

$\uparrow$ Patient satisfaction

No change in inpatient care, hospital admissions, or mortality

$\downarrow$ ED visits

Interdisciplinary care team developed, with patient, care plan based on patient's evaluation. Care plan could include goal setting, review of medication, assistance for transport, financial entitlements, and housing. The team also provided self-management support, patient education, health navigation, and care coordination.

I: $98 \quad$ Case manager developed, with patient, care plan based on patient's evaluation. Care plan could include referrals to health and social services, goal setting, assistance for transport, financial entitlements, and housing. The case manager also provided care navigation, facilitated communication with health care providers, supported interactions with community services, and provided care transition.

Interdisciplinary care team developed care plan based on patient's evaluation. The care plan could include referrals to health care services.

I: $47 \quad$ Same intervention as Brown et al (2005) ${ }^{42}$

C: 49

I: 27

C: 25

Interdisciplinary care team developed care plan based on patient's evaluation. Care plan could include care recommendation and treatment guidelines for ED staff such as limitation of diagnostic tests and restriction of narcotics prescriptions. The team also provided psychosocial services, care coordination, and liaison with a PCP.

Interdisciplinary care team developed care plan based on patient's evaluation. The care plan could include care suggestions and treatment guidelines (eg, restriction of narcotics prescriptions) for ED staff.

I: 579 Social worker case manager, with patient and other health care

c: 579 providers, developed care plan based on patient's evaluation. Care plan could include referrals to health care and social services, counseling for mental health problems, self-management support, patient activation, assistance with insurance, and medical appointment accompaniment. The case manager also provided care coordination and care transition and facilitated communication between health care providers. $\downarrow$ Hospital admission

$\downarrow$ Health care costs

$\downarrow$ ED visits

$\downarrow$ Health care cost

No change in hospital admissions or length of stay

$\downarrow$ ED visits

$\uparrow$ Clinic visits

No change in health care use or costs, functional status, patient satisfaction, or medicationtaking adherence.

No change in ED visits

$\downarrow$ ED visits

$\downarrow$ ED contact time

$\downarrow$ Laboratory tests ordered

$\downarrow$ ED costs

No change in hospital admissions 
conclude its absence/presence across all cases. Finally, the definitions of the 3 remaining main conditions were used to develop a codebook that was independently tested for clarity and comprehensiveness by reviewers outside the team. The final list of conditions and outcomes is presented in Supplemental Appendix 4 (http://www.AnnFamMed.org/content/17/4/448/suppl/ DC1/).

\section{RESULTS}

We identified 10,687 unique records, of which 10,548 did not meet the inclusion criteria (Figure 1). Among the 139 full-text articles selected, 117 were excluded based

Figure 1. Study selection process.

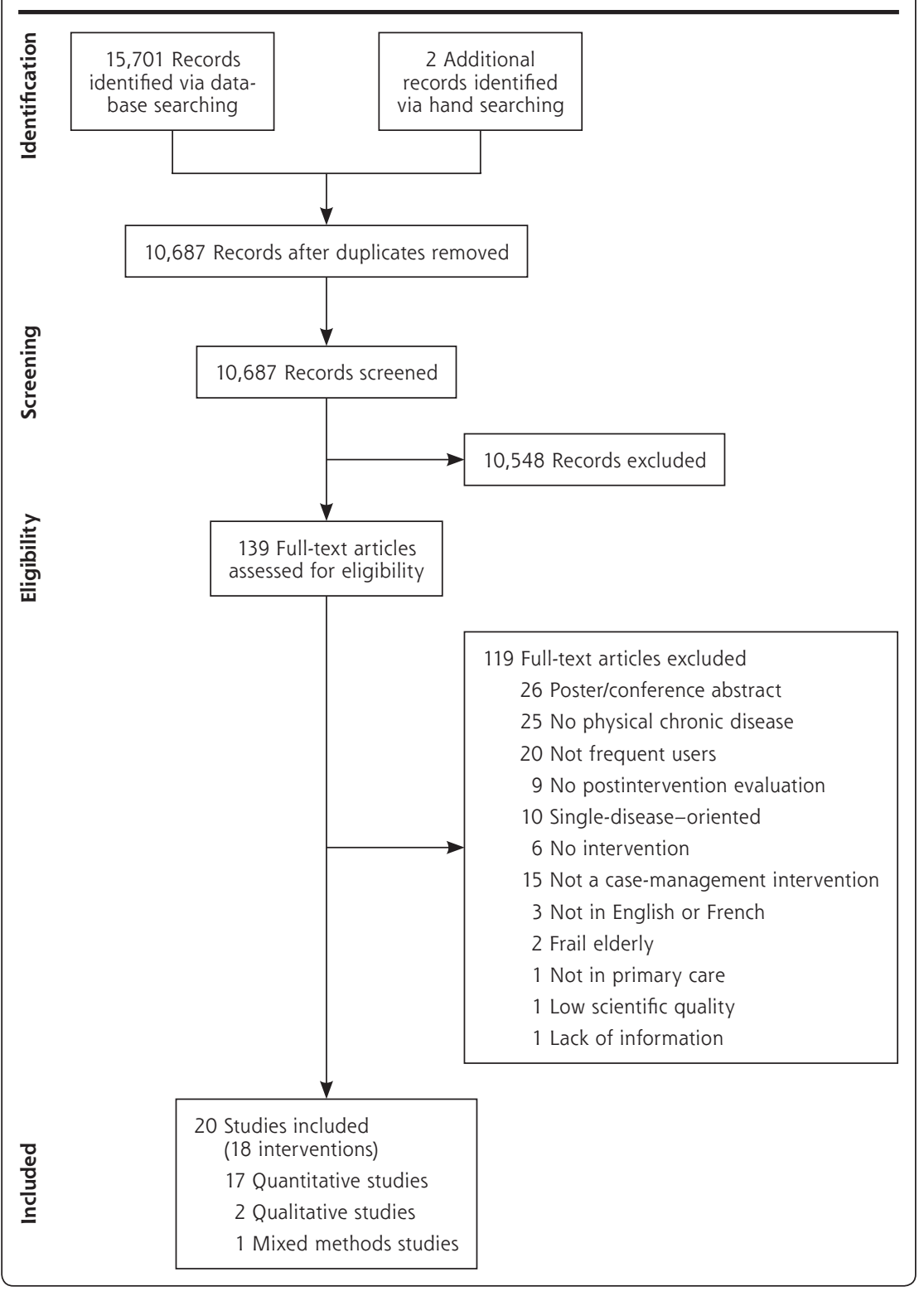

on the inclusion criteria, 1 was excluded because it did not meet the 2 initial MMAT screening questions, ${ }^{60}$ and another was excluded from the CCM analysis, owing to lack of information about the conditions (characteristics) of CM intervention in the documents. ${ }^{61}$ Thus, 20 studies (18 CM interventions) were included in the synthesis. Table 1 presents a description of these studies. Seventeen were quantitative ( 7 before-after studies, 5 nonrandomized controlled trials, and 5 randomized controlled trials), 2 were qualitative, and 1 was a mixed methods study. Twelve were conducted in United States, 2 each in Sweden and Canada, and 1 each in Switzerland, Australia, New Zealand, and the United Kingdom. The studies included 17 to 12,181 participants, with a mean age range of 20 to 66 years. The proportion of men varied from $23 \%$ to $75 \%$. All of the studies included development and implementation of a care plan, 15 involved an interdisciplinary team, ${ }^{40-43,45-47,49-51,53,55-58}$ and 11 were conducted in an ED setting. ${ }^{41,43,44,47,49-52,55,57,58}$

For the majority of studies ( $\mathrm{n}=17), \mathrm{CM}$ intervention participants were identified using a threshold of number of health care visits. ${ }^{40-44,46-50,52-57,59}$ To determine eligibility, 9 studies required patients be evaluated by a health care provider to assess their likelihood of benefiting from the $\mathrm{CM}$ intervention. .2, 44, $47-49,51,52,55,58$ Ten studies included patients with a complex/vulnerable situation such as the presence of physical, psychiatric, and/or psychosocial issues. ${ }^{40,42,43,45,46,48,51-54}$ The methodologic quality of the included studies ranged from $25 \%$ to $100 \%$ (median, $50 \%$ ).

Fifteen studies reported positive outcomes such as health and functional status, ${ }^{52}$ patient satisfaction, ${ }^{40,52}$ selfmanagement ${ }_{1}^{45,46,48} \mathrm{ED}^{42-45,47,49,51 \text { - }}$ 55,58 and clinic visits, $40,44,45,52$ hospital admission ${ }^{42,44,45,53}$ and length of stay, ${ }_{1}^{42,45,52}$ and $\mathrm{ED}^{43,44,52 \text {. }}$ $55,57,58$ and inpatient cost. $.33,44,45,52$ ${ }^{54}$ Regarding the conditions, 16 studies implemented a high-intensity CM intervent 
ion $^{40-46,48,49,51-54,56,57,59}$ including at least 3 of the following criteria: caseload of fewer than 60 patients, $\geq 50 \%$ of the time spent face-to-face with the patient, initial assessment in person, and multidisciplinary team meetings or frequent contact with the patient. Fifteen studies identified patients who could benefit the most from the $\mathrm{CM}^{40,42 \text { - }}$ $49,51-55,58$ on the basis of their identification as frequent users (with no clear definition) with complex care needs or based on providers' assessment that the CM intervention would be beneficial. Finally, 17 studies included a multidisciplinary/interorganizational care plan ${ }^{40-43,45}$. 51,53,55-59 documenting patient needs and goals as well as the available resources to respond to patients' needs and including at least 2 health care providers from disciplines other than the family physician or case manager.

Table 2 shows 5 configurations for which the casefinding condition was always present when a positive outcome occurred. In addition, the CCM revealed that the multidisciplinary/interdisciplinary care plan and the $\mathrm{CM}$ intensity conditions were often present when a positive outcome occurred. These results remained the same when we removed the studies with low methodologic quality. ${ }^{42,44,50,51}$ Supplemental Appendix 5 (http:// www.AnnFamMed.org/content/17/5/448/supp1/DC1/) illustrates the relation between the conditions and theoutcomes based on the results presented in Table 2 .

The analysis revealed that the case-finding characteristic (ie, high frequency of health care visits) and complexity of health care needs are necessary to produce a positive outcome. Moreover, in our cases, positive outcomes were associated with the following 2 sufficient characteristics when each was combined with this necessary condition: high-intensity CM intervention and presence of a multidisciplinary/interorganizational care plan.

\section{DISCUSSION}

Our findings suggest that CM should be offered to patients such as those who are uninsured, have a low income, or who a health care provider deems in need and who frequently use health care services and have complex health care needs. Such appropriate case finding should be combined with a high-intensity intervention and/or the presence of a multidisciplinary/interorganizational care plan.

Previous research, ${ }^{60,62-64}$ as well our prior thematic analysis review on key factors of CM interventions, ${ }^{65}$ have recognized the importance of appropriate patient identification. Previous studies, however, have defined the appropriateness of patient identification on the basis of patients' risk of frequent health care use and associated cost to health care systems. ${ }^{63,66,67}$ In addition to these criteria, our present results recommend a case-finding process based also on patient complex care needs (eg, combination of physical, psychiatric, and social conditions; poverty, polymedication, lack of social support, or clinical judgment). ${ }^{68}$ A combination of quantitative (eg, prediction tools and thresholds) and qualitative (eg, clinical judgment) techniques might be the best approach to identify patients for whom CM interventions will likely be most beneficial. ${ }^{64}$

The association between high-intensity CM and its effectiveness has been examined in other populations. In a systematic mixed studies review exploring the relations between positive outcomes and barriers to $\mathrm{CM}$ implementation designed for patients with dementia and their caregivers in home care programs, high-intensity CM identified with CCM was shown to be a necessary and sufficient condition to produce positive clinical outcomes and to reduce health care use. ${ }^{69}$ Similar to our present results, the importance of small caseload, regular follow-up, and multidisciplinary team meetings was highlighted. ${ }^{69}$ In addition, reviews on the effect of CM in reducing hospital use $^{70}$ and on the effectiveness of interventions in reducing ED use, ${ }^{16}$ reported that regular in-person contacts with a case manager, a criterion for highintensity $\mathrm{CM}$, might contribute to positive patient outcomes. However, others ${ }^{62}$ have reported equivocal

\begin{tabular}{|c|c|c|c|c|c|}
\hline $\begin{array}{l}\text { Case-Management } \\
\text { Intensity }\end{array}$ & $\begin{array}{l}\text { Case } \\
\text { Finding }\end{array}$ & $\begin{array}{l}\text { Multidisciplinaryl } \\
\text { Interdisciplinary } \\
\quad \text { Care Plan }\end{array}$ & $\begin{array}{l}\text { Positive } \\
\text { Outcome }\end{array}$ & $\begin{array}{l}\text { No. of } \\
\text { Cases }\end{array}$ & Cases \\
\hline 1 & 1 & 1 & 1 & 9 & 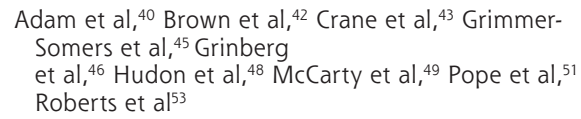 \\
\hline 1 & 1 & 0 & 1 & 3 & Edgren et al, ${ }^{44}$ Reinius et al,,$^{52}$ Shah et al ${ }^{54}$ \\
\hline 0 & 1 & 1 & 1 & 3 & Grover et al,$^{47}$ Skinner et al,$^{55}$ Stokes-Buzzelli et a ${ }^{58}$ \\
\hline 1 & 0 & 1 & 0 & 4 & $\begin{array}{l}\text { Bodenmann et al, }{ }^{41} \text { Sledge et al },^{56} \text { Spillane et al, }{ }^{57} \\
\text { Weerahandi al al, }\end{array}$ \\
\hline 0 & 0 & 1 & 0 & 1 & Peddie et also \\
\hline
\end{tabular}


results regarding the effect of high-intensity CM for patients with complex care needs and highlighted that evidence from CM interventions remains unclear. This might explain why our present CCM analysis did not identify high-intensity $\mathrm{CM}$ intervention as a necessary condition to produce positive outcomes.

Multidisciplinary teams have been recognized as an important part of $\mathrm{CM}$ interventions, ${ }^{18}$ providing the opportunity to learn from each other and offering holistic and comprehensive care for patients with complex care needs. ${ }^{62-64,71,72}$ As the coordinator of the multidisciplinary team, the case manager must ensure that patients receive coordinated and integrated care processes that guarantee quality and cost effectiveness. ${ }^{63}$ To this end, the development and implementation of a care plan is a strategy used by the case manager and best suited to align the goals of the different health care services. ${ }^{63}$ Our present review suggests that a care plan provided by health care providers from different disciplines, combined with appropriate case finding, is a strategy that will more likely be effective and result in positive $\mathrm{CM}$ outcomes.

To our knowledge, this is the first systematic review aimed at identifying characteristics of CM interventions associated with positive outcomes. Whereas a meta-analysis of quantitative results would have led to an estimate of the magnitude of the effect of CM, it would not have revealed the characteristics that are necessary and sufficient to yield the effect size. The present review used an innovative method of data analysis, CCM, which allowed us to combine quantitative, qualitative, randomized, and uncontrolled study designs in a single analysis scheme to clarify how CM leads to positive outcomes. All steps of this systematic review were confirmed by at least 2 members of the team to ensure reproducibility of the results. In addition, the systematic review process lends credence to our results, as does our sensitivity analysis, which showed that the methodologic quality of the included studies did not affect the results.

\section{Limitations}

In the present review, all outcomes were considered equal and were not analyzed individually. Second, we considered all of the eligible CM intervention studies regardless of methodologic quality. The sensitivity analysis, however, indicated that the studies with low methodologic quality did not influence the results. Third, given that the majority of the studies were implemented at a single site, results might not be generalizable to multisite health care settings. Fourth, the present review did not address the knowledge gap concerning who should deliver CM or where. Fifth, even though frequent users are a primary target of case management research, the present review did not evaluate case management for individuals with complex health care needs who are not frequent users. Finally, the primary publications often did not include enough contextual information to make a broader consideration of context possible.

\section{CONCLUSIONS}

On the basis of our results, we recommend that policy makers and clinicians focus on their case-finding processes because these comprise the essential characteristic of effective CM. Moreover, value should be placed on high-intensity CM intervention (ie, small caseload, frequent face-to-face contact with the patient, initial assessment in person, and/or multidisciplinary team meetings) and developing care plans with multiple types of care providers to help improve patient outcomes. All policy makers and clinicians directly or indirectly involved in CM now or in the future should consider adapting their decisions or practices accordingly. Further research could address how different primary care settings (eg, ED vs clinic) influence CM outcomes.

To read or post commentaries in response to this article, see it online at http://www.AnnFamMed.org/content/17/5/448.

Key words: case management; frequent users; primary health care; systematic review

Submitted October 12, 2018; submitted, revised, February 28, 2019; accepted March 29, 2019.

Author contributions: C.H. and M-C.C. conceived the review and participated in its design and coordination. F.L. and H.T.V.Z. coordinated the systematic review methods. P.P., R.S., and B.R. guided the methodologic steps of the configurational comparative methods. C.H., M-C.C., P.P., R.S., B.R., and M.L. participated in the synthesis of the data. M.L. conducted the data collection, and R.S. conducted the data analysis. M.L. drafted the manuscript under the guidance of C.H. and M-C.C. All authors made substantial contributions to the conception and design of the work and were involved in drafting and revising the manuscript.

Funding support: This project was funded by the Quebec SPORSUPPORT Unit, one of the methodologic platforms of the Canadian Institutes of Health Research (CIHR) for the Strategy for Patient-Oriented Research (SPOR). ${ }^{73}$ Members of the Unit are coauthors and offered methodologic support to design and conduct this systematic mixed studies review. The governance structures of the Unit, however, had no role in the writing of the manuscript or the decision to submit it for publication. All authors had full access to all of the data and are responsible for the decision to submit for publication.

\section{PROSPERO registration: CRD42016048006}

Acknowledgments: Special thanks to Roxanne Lépine for the development of the search strategy, as well as Léa Langlois, Véronique Gauthier, Marie-Joelle Cossi, and Michele Schemilt for screening titles and abstracts, and Catherine Vandal and the Unité de Recherche Clinique et épidémiologique du CRCHUS for administrative support.

Supplemental materials: Available at http://www.AnnFamMed. org/content/17/5/448/suppl/DC1/. 


\section{References}

1. Bodenheimer T, Berry-Millett R. Follow the money-controlling expenditures by improving care for patients needing costly services. N Engl J Med. 2009;361(16):1521-1523.

2. LaCalle E, Rabin E. Frequent users of emergency departments: the myths, the data, and the policy implications. Ann Emerg Med. 2010; $56(1): 42-48$.

3. Wodchis WP. High cost users: driving value with a patient-centred health system. Presented at: Health Links and Beyond: the Long and Winding Road to Person-Centred Care; June 20, 2013; Toronto, ON, Canada.

4. Byrne M, Murphy AW, Plunkett PK, McGee HM, Murray A, Bury $G$. Frequent attenders to an emergency department: a study of primary health care use, medical profile, and psychosocial characteristics. Ann Emerg Med. 2003;41(3):309-318.

5. Vedsted $P$, Christensen MB. Frequent attenders in general practice care: a literature review with special reference to methodological considerations. Public Health. 2005;119(2):118-137.

6. Hudon C, Sanche S, Haggerty JL. Personal characteristics and experience of primary care predicting frequent use of emergency department: a prospective cohort study. PLoS One. 2016;11(6): e0157489.

7. Olsson M, Hansagi $H$. Repeated use of the emergency department: qualitative study of the patient's perspective. Emerg Med J. 2001; 18(6):430-434.

8. Winefield HR, Turnbull DA, Seiboth C, Taplin JE. Evaluating a program of psychological interventions in primary health care: consumer distress, disability and service usage. Aust N Z J Public Health. 2007:31(3):264-269.

9. Smits FT, Brouwer HJ, ter Riet G, van Weert HC. Epidemiology of frequent attenders: a 3-year historic cohort study comparing attendance, morbidity and prescriptions of one-year and persistent frequent attenders. BMC Public Health. 2009;9:36.

10. Fuda KK, Immekus R. Frequent users of Massachusetts emergency departments: a statewide analysis. Ann Emerg Med. 2006;48(1):9-16.

11. Hansagi $H$, Allebeck $P$, Edhag $O$, Magnusson G. Frequency of emergency department attendances as a predictor of mortality: nineyear follow-up of a population-based cohort. J Public Health Med. 1990;12(1):39-44.

12. Althaus F, Paroz S, Hugli O, et al. Effectiveness of interventions targeting frequent users of emergency departments: a systematic review. Ann Emerg Med. 2011;58(1):41-52.e42.

13. Haroun $D$, Smits $F$, van Etten-Jamaludin $F$, Schene $A$, van Weert $H$, Ter Riet $\mathrm{G}$. The effects of interventions on quality of life, morbidity and consultation frequency in frequent attenders in primary care: a systematic review. Eur J Gen Pract. 2016;22(2):71-82.

14. Moe J, Kirkland SW, Rawe E, et al. Effectiveness of interventions to decrease emergency department visits by adult frequent users: a systematic review. Acad Emerg Med. 2017;24(1):40-52.

15. Soril LJ, Leggett LE, Lorenzetti DL, Noseworthy TW, Clement FM. Reducing frequent visits to the emergency department: a systematic review of interventions. PLoS One. 2015;10(4):e0123660.

16. Raven MC, Kushel M, Ko MJ, Penko J, Bindman AB. The effectiveness of emergency department visit reduction programs: a systematic review. Ann Emerg Med. 2016;68(4):467-483.e415.

17. Van den Heede K, Van de Voorde C. Interventions to reduce emergency department utilisation: a review of reviews. Health Policy. 2016;120(12):1337-1349.

18. National Case Management Network of Canada. Canadian Standards of Practice in Case Management. Ottawa, Canada: National Case Management Network of Canada; 2009.

19. Kumar GS, Klein R. Effectiveness of case management strategies in reducing emergency department visits in frequent user patient populations: a systematic review. J Emerg Med. 2013;44(3):717-729.
20. Smits FT, Wittkampf KA, Schene AH, Bindels PJ, Van Weert HC. Interventions on frequent attenders in primary care: a systematic literature review. Scand J Prim Health Care. 2008;26(2):111-116.

21. Craig P, Dieppe P, Macintyre S, Michie S, Nazareth I, Petticrew M. Developing and evaluating complex interventions: the new Medical Research Council guidance. Int J Nurs Stud. 2013;50(5):587-592.

22. Hudon C, Chouinard MC, Aubrey-Bassler K, et al. Case management in primary care among frequent users of healthcare services with chronic conditions: protocol of a realist synthesis. BMJ Open. 2017;7(9):e017701.

23. Hong QN, Pluye P, Bujold M, Wassef M. Convergent and sequential synthesis designs: implications for conducting and reporting systematic reviews of qualitative and quantitative evidence. Syst Rev. 2017;6(1):61.

24. Pluye $\mathrm{P}$, Hong QN, Bush PL, Vedel I. Opening-up the definition of systematic literature review: the plurality of worldviews, methodologies and methods for reviews and syntheses. J Clin Epidemiol. 2016; 73:2-5.

25. Hudon C, Chouinard MC, Aubrey-Bassler K, et al. Effective interventions targeting frequent users of health care and social services with chronic conditions in primary care: a systematic mixed studies review. PROSPERO: International prospective register of systematic reviews. http://www.crd.york.ac.uk/PROSPERO/display_record. asp?ID = CRD42016048006. Published Sep 2016; updated Sep 22, 2016; Accessed Mar 28, 2018.

26. Pluye P, Hong QN. Combining the power of stories and the power of numbers: mixed methods research and mixed studies reviews. Annu Rev Public Health. 2014;35:29-45.

27. Pace $R$, Pluye $P$, Bartlett $G$, et al. Testing the reliability and efficiency of the pilot Mixed Methods Appraisal Tool (MMAT) for systematic mixed studies review. Int J Nurs Stud. 2012;49(1):47-53.

28. Pluye P, Gagnon MP, Griffiths F, Johnson-Lafleur J. A scoring system for appraising mixed methods research, and concomitantly appraising qualitative, quantitative and mixed methods primary studies in Mixed Studies Reviews. Int J Nurs Stud. 2009;46(4):529-546.

29. Souto RQ, Khanassov V, Hong QN, Bush PL, Vedel I, Pluye P. Systematic mixed studies reviews: updating results on the reliability and efficiency of the Mixed Methods Appraisal Tool. Int J Nurs Stud. 2015;52(1):500-501.

30. Jüni $P$, Witschi $A$, Bloch $R$, Egger $M$. The hazards of scoring the quality of clinical trials for meta-analysis. JAMA. 1999;282(11):1054-1060.

31. Hong QN, Pluye P. A conceptual framework for critical appraisal in systematic mixed studies reviews. J Mixed Methods Res. 2018.

32. Hong QN, Gonzalez-Reyes A, Pluye P. Improving the usefulness of a tool for appraising the quality of qualitative, quantitative and mixed methods studies, the Mixed Methods Appraisal Tool (MMAT). J Eval Clin Pract. 2018;24(3):459-467.

33. Hong QN, Pluye P, Fabregues $S$, et al. Improving the content validity of the mixed methods appraisal tool (MMAT): a modified e-Delphi study. J Clin Epidemiol. 2019;111:49-59.e1.

34. Hong QN, Pluye P, Fabregues S, et al. The Mixed Methods Appraisal Tool (MMAT) version 2018 for information professionals and researchers. Educ Inf. 2018;34(4):285-291.

35. Rihoux B, Ragin C. Configurational Comparative Methods: Qualitative Comparative Analysis (QCA) and Related Techniques. Thousand Oaks, CA: Sage Publications; 2008.

36. Dy SM, Garg P, Nyberg D, et al. Critical pathway effectiveness: assessing the impact of patient, hospital care, and pathway characteristics using qualitative comparative analysis. Health Serv Res. 2005;40(2):499-516.

37. Berg-Schlosser D, De Meur G, Rihoux B, Ragin CC. Qualitative Comparative Analysis (QCA) as an Approach. In: Rihoux B, Ragin C, eds. Configurational Comparative Methods. Thousand Oaks, CA: Sage Publications; 2009: 1-18. 
38. Rihoux B, Lobe B. The case for Qualitative Comparative Analysis (QCA): Adding Leverage for Thick Cross-Case Comparison. In: Byrne D, Ragin C, eds. The Sage Handbook of Case-Based Methods. London, England: Sage; 2009.

39. Marx A, Dusa A. Crisp-Set Qualitative Comparative Analysis (csQCA), contradictions and consistency benchmarks for model specification. Methodol Innov Online. 2011;6(2):103-148.

40. Adam P, Brandenburg DL, Bremer KL, Nordstrom DL. Effects of team care of frequent attenders on patients and physicians. Fam Syst Health. 2010;28(3):247-257.

41. Bodenmann P, Velonaki VS, Griffin JL, et al. Case management may reduce emergency department frequent use in a universal health coverage system: a randomized controlled trial. J Gen Intern Med. 2017;32(5):508-515.

42. Brown KE, Levine JM, Fiellin DA, O'Connor P, Sledge WH. Primary intensive care: pilot study of a primary care-based intervention for high-utilizing patients. Dis Manag. 2005;8(3):169-177.

43. Crane S, Collins L, Hall J, Rochester D, Patch S. Reducing utilization by uninsured frequent users of the emergency department: combining case management and drop-in group medical appointments. J Am Board Fam Med. 2012;25(2):184-191.

44. Edgren G, Anderson J, Dolk A, et al. A case management intervention targeted to reduce healthcare consumption for frequent Emergency Department visitors: results from an adaptive randomized trial. Eur J Emerg Med. 2016;23(5):344-350.

45. Grimmer-Somers K, Johnston K, Somers E, Luker J, Alemao LA, Jones $D$. A holistic client-centred program for vulnerable frequent hospital attenders: cost efficiencies and changed practices. Aust N Z J Public Health. 2010;34(6):609-612.

46. Grinberg C, Hawthorne M, LaNoue M, Brenner J, Mautner D. The core of care management: the role of authentic relationships in caring for patients with frequent hospitalizations. Popul Health Manag. 2016;19(4):248-256.

47. Grover CA, Close RJ, Villarreal K, Goldman LM. Emergency department frequent user: pilot study of intensive case management to reduce visits and computed tomography. West J Emerg Med. 2010; 11(4):336-343.

48. Hudon C, Chouinard MC, Diadiou F, Lambert M, Bouliane D. Case management in primary care for frequent users of health care services with chronic diseases: a qualitative study of patient and family experience. Ann Fam Med. 2015;13(6):523-528.

49. McCarty RL, Zarn J, Fenn R, Collins RD. Frequent ED utilizers: a case management program to address patient needs. Nurs Manage. 2015;46(9):24-31; quiz 31-22.

50. Peddie S, Richardson S, Salt L, Ardagh M. Frequent attenders at emergency departments: research regarding the utility of management plans fails to take into account the natural attrition of attendance. N Z Med J. 2011;124(1331):61-66.

51. Pope D, Fernandes CM, Bouthillette F, Etherington J. Frequent users of the emergency department: a program to improve care and reduce visits. CMAJ. 2000;162(7):1017-1020.

52. Reinius $P$, Johansson $M$, Fjellner $A$, Werr J, Ohlén $G$, Edgren $G$. A telephone-based case-management intervention reduces healthcare utilization for frequent emergency department visitors. Eur J Emerg Med. 2013;20(5):327-334.

53. Roberts SR, Crigler J, Ramirez C, Sisco D, Early GL. Working with socially and medically complex patients: when care transitions are circular, overlapping, and continual rather than linear and finite. J Healthe Qual. 2015;37(4):245-265.

54. Shah R, Chen C, O'Rourke S, Lee M, Mohanty SA, Abraham J. Evaluation of care management for the uninsured. Med Care. 2011; 49(2):166-171.
55. Skinner J, Carter L, Haxton C. Case management of patients who frequently present to a Scottish emergency department. Emerg Med J. 2009;26(2):103-105.

56. Sledge WH, Brown KE, Levine JM, et al. A randomized trial of primary intensive care to reduce hospital admissions in patients with high utilization of inpatient services. Dis Manag. 2006;9(6):328-338.

57. Spillane LL, Lumb EW, Cobaugh DJ, Wilcox SR, Clark JS, Schneider $S M$. Frequent users of the emergency department: can we intervene? Acad Emerg Med. 1997;4(6):574-580.

58. Stokes-Buzzelli S, Peltzer-Jones JM, Martin GB, Ford MM, Weise A. Use of health information technology to manage frequently presenting emergency department patients. West J Emerg Med. 2010; 11(4):348-353.

59. Weerahandi H, Basso Lipani M, Kalman J, et al. Effects of a psychosocial transitional care model on hospitalizations and cost of care for high utilizers. Soc Work Health Care. 2015;54(6):485-498.

60. Dattalo M, Nothelle $S$, Tackett $S$, et al. Frontline account: targeting hot spotters in an internal medicine residency clinic. J Gen Intern Med. 2014;29(9):1305-1307.

61. Navratil-Strawn JL, Hawkins K, Wells TS, et al. An emergency room decision-support program that increased physician office visits, decreased emergency room visits, and saved money. Popul Health Manag. 2014;17(5):257-264.

62. Bodenheimer TS, Berry-Millett R. Care Management of Patients With Complex Health Care Needs. Princeton, NJ: Robert Wood Johnson Foundation; 2009.

63. Ross S, Curry N, Goodwin N. Case Management: What It Is and How It Can Best Be Implemented. London, UK: The King's Funds; 2011.

64. Hong CS, Siegel AL, Ferris TG. Caring for high-need, high-cost patients: what makes for a successful care management program? Issue Brief (Commonw Fund). 2014;19:1-19.

65. Hudon C, Chouinard MC, Lambert M, Diadiou F, Bouliane D, Beaudin J. Key factors of case management interventions for frequent users of healthcare services: a thematic analysis review. BMJ Open. 2017;7(10):e017762.

66. Stokes J, Panagioti M, Alam R, Checkland K, Cheraghi-Sohi S, Bower P. Effectiveness of case management for 'at risk' patients in primary care: a systematic review and meta-analysis. PLoS One. 2015;10(7):e0132340.

67. Billings J, Dixon J, Mijanovich T, Wennberg D. Case finding for patients at risk of readmission to hospital: development of algorithm to identify high risk patients. BMJ. 2006;333(7563):327.

68. Bodenmann $P$, Baggio S, Iglesias $K$, et al. Characterizing the vulnerability of frequent emergency department users by applying a conceptual framework: a controlled, cross-sectional study. Int J Equity Health. 2015;14:146.

69. Khanassov V, Vedel I, Pluye P. Barriers to implementation of case management for patients with dementia: a systematic mixed studies review. Ann Fam Med. 2014;12(5):456-465.

70. Joo JY, Liu MF. Case management effectiveness in reducing hospital use: a systematic review. Int Nurs Rev. 2017;64(2):296-308.

71. Trella RS. A multidisciplinary approach to case management of frail, hospitalized older adults. J Nurs Adm. 1993;23(2):20-26.

72. de Stampa M, Vedel I, Trouvé H, Ankri J, Saint Jean O, Somme D. Multidisciplinary teams of case managers in the implementation of an innovative integrated services delivery for the elderly in France. BMC Health Serv Res. 2014;14:159.

73. Canadian Institutes of Health Research. Strategy for PatientOriented Research. http://www.cihr-irsc.gc.ca/e/41204.html. Accessed Apr 18, 2018. 